\title{
La Biblioteca de José Cemí
}

Como toda obra mayor, Paradiso es una novela cuya novedad expresiva es también una libre relectura de la tradición.

Ya en su último ensayo de La expresión americana (1957) Lezama Lima nos advertía que la actividad del cambio desarrollada por los principales protagonistas de la ruptura naturalista de los años 20 (Joyce, Picasso, Stravinsky), se basaba en una nueva actitud ante el trabajo con las formas; en primer lugar, en la superación del historicismo, lo que permitía asumir la tradición cultural de un modo activo; en segundo lugar, esa tradición fue entendida como saber crítico, y así la crítica era parte de la actividad creadora. Paradiso también discute estas relaciones de cambio y tradición precisando que "una recta interpretación del pasado" supone su reavivamiento, y desde alli la búsqueda de lo nuevo. Fronesis y Cemi, dice la novela, "Sabian que el conformismo en la expresión y en las ideas, tomaba en el mundo contemporáneo innumerables variantes y disfraces, pues exigian del intelectual la servidumbre, el mecanismo de un absoluto causal, para que abandonase su posición verdaderamente heroica de ser, como en las grandes épocas, creador de valores, de formas, el saludador de lo viviente creador y acusador de lo amortajado en bloques de hielo, que tadavía osa fluir en el río de lo temporal" (p. 439). Por ello, ocurre que en la obra de Lezama la novedad expresiva ya no es una derivación historicista, otra forma de las vanguardias, sino más bien el tratamiento ficcional de la tradición, su libre empleo como lenguaje. La tradición es un presente cambiante, y la perspectiva crítica el instrumento que reordena ese diálogo.

"Nuestro método quisiera más acercarse a esa técnica de la ficción, preconizada por Curtius, que al método mítico critico de Eliot", escribe en el primer ensayo de $L a$ expresion americana. Lezama critica aqui la perspectiva neoclasicista de Eliot, basada en la actividad de la glosa y en la creencia de que la tradición es un modelo estable, del cual la poesía contemporánea sería el reflejo fragmentario. Observemos, de paso, que esta crítica alcanza también a Borges, para quien la literatura es una realidad ya dada, lo mismo que los autores y el repertorio de los temas fundamentales, y, por ello, la glosa y la escritura crítica son el modus operandis de una ticción combinatoria; aunque hay que anadir inmediatamenteque esta actividad borgiana es asimismo una libre relectura de la tradición. El 
método que propone Lezama es, por cierto, el opuesto: la expansión proliferante de la escritura. "Todo tendrá que ser reconstruido, invencionado de nuevo, y los viejos mitos, al reaparecer de nuevo, nos ofrecerán sus conjuros y sus enigmas con un rostro desconocido. La ficción de los mitos son nuevos mitos, con nuevos cansancios y terrores", escribe.

El punto de vista sobre la tradición debe ser otro: en lugar de la historia cultural, la recuperación de las "eras imaginarias". Y aquí radica el centro del cambio para Lezama: la tradición deja de ser una cronología evolucionista y se convierte en una alternancia de la ficción. Un objeto, un texto, un héroe son signos definidos por la peculiaridad ficticia de un periodo, porque la historia humana es aquí entendida como el ciclo configurador de lo imaginario. Dante nos recordaba en El Convivio que la naturaleza humana se define en la sabiduria, en su búsqueda; este principio aristotélico es modificado por Lezama: todo indica que aqứ la naturaleza humana se define por la imaginación. Sólo que esta imaginación es entendida como un sistema de conocimiento desde la necesidad unitaria y reveladora que sustenta a su obra.

Esa necesidad unitaria se cumple en Lezama por lo menos a partir de dos fuentes proyectivas. La primera hunde sus raíces en nuestra tradición más característica: el pensamiento cristiano; la segunda, en la tradición órfica: la fe en la poesía como camino de conocimiento. Ambas fuentes se unen en su obra, porque se equivalen: la experiencia poética es también una forma de la experiencia religiosa; y ésta, a su vez, aparece aquí como el universalismo de lo católico, que ya había precisado Paul Claudel. Sin embargo, hay que añadir que la vida peculiar de esa obra, su especifica manera de originarse en esas fuentes, sólo puede comprenderse por el hecho de su otro origen. Su origen americano, quiero decir. Borges nos había advertido que la cultura occidental es también nuestro pasado, y que nuestro manejo de la tradición nos hacía libres en ella. Lezama Lima extrema esta certidumbre; no es casual que sea en La expresion americana donde encontremos su teoría de las eras imaginarias, y el rico deslinde de una perspectiva integradora.

Ahora bien, esa perspectiva que convierte en era imaginaria la historia cultural, parte ciertamente de su fe absoluta en la palabra poética. En Paradiso, como en su obra toda, la poesia es la confluencia de caminos: el punto nuclear, desde donde se ordena la realidad - la naturaleza, como prefiere él - revelándose al convertirse en lenguaje. El cambio radica aquí en el tratamiento de la tradición desde la perspectiva de la poesía : la cultura se transforma en imagen, la historia en ficción, el hombre en metáfora. La audacia expresiva de esta novela es otra forma de su audacia cultural.

Por lo mismo, más que una lectura de fuentes, Paradiso nos reclama una lectura de correlaciones. Lezama ya no inventa a sus precursores, su libro suscita una biblioteca: la biblioteca de la tradición, de una tradición ritualizada por la poesia, convertida así en nueva imagen del mundo. Precisamente, los modelos formales donde esa transformación ocurre son en esta novela el marco del aprendizaje poético y el ciclo de las iniciaciones que tal aventura reclama. Estos modelos suponen, por cierto, la "'novela de educación' (el libro de Proust, el joven artista de Joyce) pero sobre todo deducen un diálogo con algunos libros del romanticismo alemán; con el Wilhelm Meister de Goethe, y, especialmente, con el Heinrich von Ofterdingen de Novalis. En efecto, la inconclusa novela de Novalis se 
desarrolla como un ciclo de iniciaciones por el cual el joven aprendiz de poeta va ingresando a una realidad definida por la búsqueda de la poesía absoluta. Esa ritualización del destino es también esencial al progreso poético de José Cemí. Y esta es la estructura interna de la novela de Lezama: los sucesivos encuentros de Cemí van construyendo las fases del relato, orientadas hacia el reconocimiento de un destino verbal.

Pero este diálogo con Novalis va más allá del modelo formal. Así, el tema de la enfermedad como un indicio sobre el destino individual aparece en Paradiso referido a las relaciones del asma de José Cemí y el ritmo respiratorio de la poesía. La novela empieza precisamente con una prolija descripción de los efectos del asma en Cemín niño, y esa enfermedad (que en su sugerencia infernal probablemente alegoriza también la idea del pecado en el origen) será la imagen de una resistencia, equivalente a la otra resistencia que Lezama nos dice es connatural a la poesía misma. Si la poesía es conversión verbal, Lezama explica que antes es una resistencia que nos desafia y nos tienta; asi, el asma parece, en el destino de José Cemí, la imagen de una lucha más interna, el indicio de que el ritmo hesicástico (el armonioso ritmo del mundo que la poesía reconduce) debe ser logrado desde un desenlace personal. Y aqui conviene recordar que en el sistema poético de Lezama la realidad nunca es opcional o excluyente, sino que integra siempre los polos discordantes (el peligro y el desenlace, el castigo y el fervor, la muerte y la resurrección) en una figura ampliada por las confluencias. Por eso, el asma (respiración amenzada) es el otro lado de la poesía (respiración armónica), pero también su necesaria tensión y resistencia.

Pues bien, esta elaboración sobre la enfermedad aparecía en los Fragmentos de Novalis como una especulación posible. “ ¿No podria la enfermedad ser un medio de síntesis superior, y cuanto más espantosa la enfermedad, más elevada la voluptuosidad que se oculta en ella?", se pregunta Novalis. Dice también: "El sistema de la moral debe convertirse en el sistema de la naturaleza. Todas las enfermedades se asemejan al pecado porque son trascendencias; todas nuestras enfermedades son fenómenos de la sensación engrandecida que quiere transformarse en fuerzas superiores." Este es el punto en que Lezama se encuentra con Novalis: la trascendencia de la enfermedad, en tanto imagen del pecado, hacia una derivación moral que a su vez configura a la naturaleza; a través de la poesía en la respuesta de Lezama. "Sólo conocemos - concluía Novalis - de modo muy imperfecto aún, el arte de utilizarlas". En el fondo, la operación se hace idéntica en la necesidad de que la naturaleza humana y sus transformaciones adquiera un sentido configurativo en contra de cualquier posibilidad de errancia o sinsentido.

Pero veamos ahora una correlación más importante. Uno de los Fragmentos nos dice: "La poesía de la naturaleza es, ciertamente, el propio objeto de la poesía artística; y las expresiones del lenguaje poético parecen ser fórmulas singulares de relaciones análogas, signos simbólicos de lo poético que hay en la apariencia'. Esta idea de Novalis nos lleva al centro del mundo de Lezama. En efecto, Novalis nos dice aquí que el lenguaje poético es la versión simbólica o análoga del otro lenguaje del mundo, de la escritura que nos habla desde la naturaleza. El mundo como una escritura: este tema de la tradición reaparece en Lezama, desde una perspectiva notablemente renovada, como veremos luego. De paso, diremos que el tema aparece también, y de modo no menos central, en Borges; y podemos seguirlo asimismo en Rayuela de Julio Cortázar, en la poesía de Octavio Paz, en las novelas de Alejo Carpentier. 
Novalis recupera este tema de la tradición mística (tal vez a partir de sus lecturas de Boehme, quien lo habia desarrollado en su tratado De Signatura Rerum) y lo plantea especulativamente en Los discipulos en Sais, donde leemos: "Los hombres marchan por distintos caminos; quien los siga y compare, verá surgir extrañas figuras; figuras que parecen pertenecer a aquella escritura difficil y caprichosa que se encuentra en todas partes: sobre las alas, sobre la cáscara de los huevos, en las nubes, en la nieve, en los cristales, en la configuración de las rocas, sobre el agua congelada, dentro y fuera de las montanas, de las plantas, de los animales, de los hombres, en los resplandores del cielo, sobre los discos de vidrio y de resina, cuando se frotan y palpan; en las limaduras que se adhieren al imán y en las extrañas conjeturas del azar..." En su crónica "Epifanía en el paisaje" (Tratados en La Habana) Lezama Lima escribe: "Don Aire, ¿a dónde va tu lección?", y también: "La luz fría es la que rectifica. $\mathrm{Y}$ aquí la luz impulsó a las arenas, dictó como leyendo en pergamino por debajo del mar, las órdenes de la batalla"'. En Paradiso, cuando muere Licario, leemos que "Su cuerpo ya no paseaba por las azoteas, para fijar la errante lectura de los astros". Pero, como siempre, la respuesta de Lezama no irá a ser literal.sino, más bien, un trastocamiento.

El primer nivel de este tema se sitúa en la evidencia que señala Claudel, en su ensayo sobre el Igitur de Mallarmé: "Sabemos por la Escritura que el mundo es un libro escrito al revés y al derecho (este libro del cual Igitur intentaba establecer un facsímil) y que las cosas visibles están hechas para conducirnos al conocimiento de las cosas invisibles". Pero ya el propio Novalis había ido más allá de esa evidencia cuando percibía la necesidad de establecer una lectura-escritura de acceso entre el mundo interior y el mundo exterior. "No es menester que busquemos mucho: una comparación rápida, algunos trazos sobre la arena, bastan para hacernos comprender. Todo se vuelve un extensisimo criptograma cuya clave poseemos", escribió. La orientación mística de su pensamiento le llevaria a la nostalgia de una edad dorada, en la cual la lectura del mundo sería transparente gracias a un lenguaje primigenio, hoy perdido; pero Novalis no se detiene en esa añoranza y se adentra en la búsqueda de relaciones confluentes, o al menos en su planteamiento, superando también la tentación, animista del paisaje. Esta búsqueda le conduce a advertir la condición todavía inédita de esas relaciones: "Hay que reconocer también que, en general, es preciso haber adquirido el hábito de pensar de mil modos distintos, para poder abordar la composición interior de nuestro cuerpo y aplicar su inteligencia a la de la Naturaleza; y nada sería más lógico que suscitar todos los movimientos del pensamiento que se pueda..." Esta idea lo lleva a plantear una sugerencia, cuya penetración nos interesa aquí: "Si pudieran obtenerse de este modo, algunos movimientos que llegaran a ser algo así como el alfabeto de la Naturaleza, resultaria cada vez más fácil descifrarla; y el poder que el observador hubiese adquirido sobre la generación del pensamiento y las emociones, o los movimientos, le permitiria hacer surgir pensamientos naturales y bosquejar composiciones, naturales también, aun en el caso de que no existiese impresión real antecedente; de esa manera, se habría llegado a la meta"'.

Es sorprendente la relación de esta idea de Novalis con la idea de la sobrenaturaleza que diseña Lezama. El tema de la escritura del mundo evoluciona en Los discipulos en Sais hacia esta invención de un alfabeto de la Naturaleza; código abierto, que permitirfa un proceso de invención desde el sujeto que se descifra a sí mismo en el objeto. Pero la vin- 
culación con Lezama proviene del paso siguiente de Novalis: la posibilidad de un sistema para suscitar ese alfabeto del mundo. Escribió Novalis: "¿No os parece que el futuro geógrafo de la Naturaleza podrá obtener, precisamente de los sistemas bien combinados, los puntos de mira de su gran mapa de la Naturaleza? Los comparará entre sí, y esa comparación ha de enseñarnos a conocer, ante todo, la tierra singular'. Estudiando la Naturaleza, concluye, "se creará un sistema...fundado en la experiencia, el análisis y la comparación. Se asimilará dicho sistema hasta que se le haya convertido en algo semejante a una segunda naturaleza..." Esa segunda naturaleza es, justamente, lo que Lezama Lima ha llamado sobrenaturaleza, aun cuando ésta excede el esquema de Novalis al integrar también el manejo de la cultura.

En su ensayo "Pascal y la poesía", Lezama sugiere la necesidad de "la elaboración de la naturaleza en el hombre", la cual reemplace o salde la situación de la "naturaleza caída" que nos define desde el pecado. "Fabricar naturaleza-concluye- es por ello una obligación". La sobrenaturaleza, de este modo sería la transformación de la naturaleza en morada humana; su lectura, ya no solamente como evidencia que oculta y dicta un mensaje, sino como figura e imagen; como actividad figurativa que abre un espacio nuevo y suficiente. Así, la sobrenaturaleza no alude sólo al mundo exterior: es el mundo en tanto espacio de conocimiento; y en ella se encuentran tanto el lenguaje de la poesía como la mirada que suscita la epifanía del paisaje.

En Lezama el mundo no nos habla con un lenguaje cifrado, nos habla con una figuración confluente. Los objetos se transforman en imágenes y éstas a su vez en espacio poético, en "espacio gnóstico" como dice él. La naturaleza invencionada que reclamó Novalis aparece aquí como la sobrenaturaleza que conjuga el leer y el escribir de la poesía con el vivir renovado del mundo. En Paradiso la descripción del trabajo poético de Cemí implica estas conjunciones:

El ejercicio de la poesía, la búsqueda verbal de finalidad desconocida, le iba desarrollando una extraña percepción por las palabras que adquieren un relieve animista en los agrupamientos espaciales, sentadas como sibilas en una asamblea de espíritus. Cuando su visión le entregaba una palabra en cualquier relación que pudiera tener con la realidad, esa palabra le parecía que pasaba a sus manos, y aunque la palabra le permaneciese invisible, liberada de la visión de donde había partido, iba adquiriendo una rueda donde giraba incesantemente la modulación invisible y la modelación palpable...Así fue adquiriendo la ambivalencia ante el espacio gnóstico, el que expresa, el que conoce, el de la diferencia de densidad que se contrae para parir, y la cantidad, que en unidad de tiempo, reaviva la mirada, el carácter sagrado de lo que en un instante pasa de la visión que ondula a la mirada que se fija. Espacio gnóstico, árbol, hombre, ciudad, agrupamientos espaciales donde el hombre es el punto medio entre naturaleza y sobrenaturaleza.

Es así que la palabra y la mirada son formas suscitadoras de un territorio donde la realidad es siempre ampliada. El lenguaje incluso antecede a lo real, lo convoca y formuliza. La naturaleza es la potencialidad de una abundancia mítica, siempre a punto de convertirse en una sobrerealidad encantatoria.

Oppiano Licario nos dice: “¿Si no es por la ocasión, remolino de coincidencias que se 
detienen en escultura, cómo podríamos mostrar la sabiduría? La vida es una red de situaciones indeterminadas, cada coincidencia es algo que quiere hablar a nuestro lado, si la interpretamos incorporamos una forma, dominamos una transparencia". Esta lectura de las coincidencias evoca también la lectura del "azar objetivo" que intentó Bretón y el surrealismo; en la empresa de Lezama como en las correlaciones de Bretón, el punto de partida es similar: la analogía, que establece un nuevo campo de correspondencias. En su ensayo "Corona de lo informe" Lezama advierte: "Ya la forma no puede ser definida como la etapa última de la materia, sino como el momento más eficaz para que el movimiento pueda ser captado sin ser detenido"; y añade: "El verdadero espíritu clásico no rehusa la mordida de la sierpe'. La analogía, por ello, es el movimiento de conversión por excelencia: no establece una forma final sino una forma de mediaciones convergentes, que Bretón llamó con justicia "los vasos comunicantes"'; figura en cuya rotación la errancia de lo vivido gana un lenguaje, y con él su sentido. Por eso, Oppiano Licario reitera: "Lo único que puede interesarme es la coincidencia de mi yo en la diversidad de las situaciones. Si dejo de pasar esas coincidencias, me siento morir cuando las interpreto, soy el artífice de un milagro, he dominado el acto informe de la naturaleza'.

"El acto informe de la naturaleza"; esta frase nos hace recordar que a pesar de sus relaciones con el romanticismo alemán y con la tradición mística, Lezama Lima ha percibido también la noche y la mudez de la naturaleza en Baudelaire, y la mudez y el vacío del mundo en Mallarmé. Pero aun así, no hay que creer que la naturaleza sea para Lezama un acto informe como tal, sino que en su potencialidad lo informe "se presenta como el devenir al ser apresado, al obtener su coronación". Es en este sentido que La expresion americana afirma que la imagen se constituye en "paisaje de cultura" como producto del enfrentamiento de la naturaleza y el hombre. Ello revela que en Lezama el espacio desértico y abismante que es el mundo de la poesía moderna, está siempre convergiendo como morada a partir de la palabra y la imagen.

Podemos, pues, afirmar que en Lezama el tema tradicional de la escritura del mundo ha sido transformado en la figuración incesante de la naturaleza. Así, de la memoria de la abuela Mela nos dice la novela que " Allí el tiempo era una gárgola, que al hablar regalaba los dones de la inmortalidad, pero con la boda cerrada parecía petrificar los hechos, congelar las fuentes. De su boca saltaba el tiempo disfrazado, el hecho que se arrastraba como un fuego fatuo por una llanura que crujía al recibir el deshielo. Por su boca no entraban los ordenamientos del tiempo ni los silencios de los que en el comedor estaban jugando a las barajas, pero muy pronto aquella conversación fantasmal los trocaba a ellos ambién en fantasmas, pareciendo opulentos señores feudales, que leían en las tablas del 'Tarot los próximos lamentos de sus desdichas..." Encontramos aquí la clave de la transformación de este tema: el tiempo habla por la memoria de la abuela, pero ya de otro modo, como otro sistema; no estamos ante el tiempo natural sino ante un tiempo sobrereal; no ante la escritura nominal del mundo sino ante la figuración metafórica del mundo. Por lo tanto, la clave de esta perspectiva está en el signo barroco de la escritura de Lezama: - es en la hipérbole del barroco donde la naturaleza se trueca en sobrenaturaleza, donde la realidad se reconoce como espacio de la imagen y el mundo como morada verbal.

También las ronchas que los ataques del asma producen en el cuerpo de Cemí son como un lenguaje de figuras; y el asma como la resistencia del habla: "Cada sueño que no 
puede contar lo ahoga, ahí está ya el asma", dice Rialta de su hijo. Cuando todavía niño Cemí se enfrenta a una estatua de cera, la novela nos dice: "Que allí no había una imagen siquiera, sino un corrientísimo molde de cera, ni siquiera trabajando con un exceso de realismo que se prestara a la confusión, no podía ser precisado por Cemí, a sus seis años, en que iba descubriendo los objetos, pero sin tener una masa en extenso que fuera propicia en la formación de los análogos y a los agrupamientos de las desemejanzas en torno a núcleos de distribución y nuevos ordenamientos". Lo cual sugiere que la evidencia nominal de los objetos es insuficiente: Cemí deberá recorrer un largo camino de aprendizaje antes de poder leer la realidad desde la analogía y desde la metáfora. Cuando Rialta y sus hijos juegan a los yaquis y aparece en las losetas del patio la figura del padre muerto, nos encontramos con ese otro lenguaje de la figuración. "Un rápido animismo iba transmutando las losetas, como si aquel mundo inorgánico se fuese transfundiendo en el cosmos receptivo de la imagen"'. El mundo habla a través de la imagen, desde el poder suscitador de la mirada, y en la actividad de la luz; buscar en lo manifestado lo oculto, " en lo secreto lo que asciende para que la luz lo configure' es la obsesión que Rialta reclama para Cemí.

Lezama mismo nos advierte (a propósito de la amistad de Fronesis y Cemí) contra " $\mathrm{el}$ romanticismo superficial de la unión de los complementarios", porque no se busca en esta figuración simplemente una armonía conciliadora, sino la creación de nuevos espacios a través del lenguaje. De Cemí la novela dice que "Causaba la sensación de ser el transmutador de las horas, tenía el secreto de las metamorfosis del tiempo, las horas habitadas por un lirón o por una Emys Rugosa, las trocaba en horas de halcón o en las de un gato de electrizado bigote"'. Aquí la palabra clave, como antes a propósito de la memoria de la abuela, es trocar: la figuración otra vez. En "Epifanía del paisaje" se lee: "Pero ahí en Viñales los ojos no definen, musicalizan lo sumergido". Por lo demás, el amplio uso distributivo de las fórmulas "como", "parecía", "igual a", "semejante a", etc., indican la proliferación de estos trastocamientos, la conversión figurativa de una escritura barroca.

Pero entre el mundo como un lenguaje que nos habla y el mundo como lugar del extrañamiento - entre la naturaleza que se hace leer y la naturaleza aislada por la conciencia - sin duda que Lezama Lima propone otra alternativa. Parte de la naturaleza simbólica de los románticos, pero todo indica que la trasciende; y tampoco coincide con la indeferencia del mundo que propone una parte de la poesía moderna. En su ensayo sobre Igitur, Claudel escribe: "Sabemos que el mundo es en efecto un texto y que nos habla, humilde y alegremente, de su propia ausencia, pero también de la presencia eterna de alguien más, su creador"'. Es posible que Lezama coincida con esta afirmación de Claudel, cuya "salud salvaje" él mismo ha destacado en nombre de "el apetito" como "alegría que incorpora". Pero es posible también que su visión religiosa no se entregue a una mecánica trascendentalista, sino que la inmanencia del mundo sea para él más tangible, y también desde una perspectiva que asume la trascendencia en los trabajos reveladores de la palabra. Por eso, cuando todo parece llevarlo a Claudel, hay una conciencia crítica e instrumental que parece acercarlo a Mallarmé. En sus ensayos sobre Mallarmé, Lezama no sólo muestra su viva adhesión a un trabajo poético que se cumple de modo radical, en el ámbito de una palabra que brilla entre "la multiplicidad del vacío y de los sentidos"; también traza una peculiar parábola cuando afirma que "tres siglos después parece como si Mallarmé hubiese escrito la mitología que debe servir de pórtico a Don Luis de Góngora'". Así, no sigue a 
Mallarmé en su experiencia del vacío y del silencio, sino en la figuración que hace de la realidad un destello de imágenes y, más esencialmente, un rumor; en su poesía, Lezama parece llevar el trastocamiento de la imagen hacia el rumor de los sentidos. De Mallarmé a Góngora, Lezama traza de este modo una parábola de la analogía: el espacio equivalente de Mallarmé, la hipérbole de Góngora y la figuración de Lezama coinciden en la autonomía de la imagen, en su poder trastocador. Cualquiera de los tres pudo haber escrito el verso " No es sordo el mar: la erudición engaña" , que está en las Soledades, y que precisamente alude a una tradición vuelta a leer, a una poesía que vuelve a nombrar.

Es preciso analizar ahora los procedimientos expresivos del sistema poético que funciona en Paradiso. El reclamo por un sistema que hizo Novalis, adquiere en esta novela un desarrollo inusitado. Para la poesía Lezama ha intentado precisar un sistema suyo, basado en métodos de suscitamiento, como la memoria hiperbólica y la vivencia oblicua. Pero es en su novela donde una metodología inducirá la construcción de aquel sistema. Lezama parte para ello de las posibilidades asociativas de la analogía y la șemejanza. No se trata ya aquí del funcionamiento clásico de la semejanza, del cual dice bien Michel. Foucault (en Las palabras y las cosas) que presupone la identidad del mundo consigo mìsmo; esta tautológica construcción finalmente conduce a la abolición de los términos; y hay que añadir que precisamente una reflexión paralela sobre los mecanismos de la analogía parece implícita en Paradiso, según se deduce de la alusión a Narciso. (pag. 391) que hace Foción: "Señalaba el Narciso y decía: la imagen de la imagen, la nada". Se trata aquí, más bien, de la semejanza en el esquema de la metáfora. O sea, de una semejanza de términos contrarios que ganan su nueva afinidad al producir la coincidencia de un término tercero. Como en la Comedia de Dante, en el Paradiso de Lezama la construcción interior del texto y el sistema de aprehensión obedecen a esta metodología de la tríada.

En efecto, la triada de elementos parece ser la forma metódica de esta novela, aunque no en nombre de un rigor sistemático, sino más bien en la posibilidad de suscitamiento metafórico que permite este esquema. Antes, pues, que estar ante una organización prolija, estamos ante una tendencia mitopoética. Por cierto, este método reconoce y recupera los valores tradicionales (sabemos que la tríada es en la Comedia más que organización) si bien aparece aquí, en primer lugar, como método de composición y de escritura. En L'ésotérisme de Dante René Guénon ha analizado las deducciones simbólicas de la Comedia, estableciendo para la numerologia una interpretación de carácter iniciático; este nivel sería el cuarto y más interno de aquellos cuatro planos de la lectura que Dante señaló en el Convivio. También en la novela de Lezama observamos varios niveles implicados en el uso de la tríada. En primer término, aparece como el esquema de la acción: los hechos y los personajes se desenvuelven por acción de un tercer elemento, sugiriendo así que el tercer término de la figura deduce un destino. Cuando el coronel Cemí conoce a Alberto Olalla, la triada se establece con la nueva presencia de Rialta. Este esquema se reitera en la amistad (Cemí, Foción, Fronesis), en el ciclo de las iniciaciones (la madre, el tío Alberto, Oppiano Licario), así como en los laberintos familiares de Fronesis (el padre, la madre huída, la madre reemplazante) y de Foción (el padre, la madre infiel, el tío muerto). Precisamente cuando narra el episodio sobre los padres de Foción, el autor nos dice: "Pero faltaba, tal vez, una tercera figura en esa trágica composición: la locura", porque al descubrir la infidelidad el padre pierde la razón. En la misma escritura aparece también este esquema de composición. Cuando Foción quiere definir Nueva York, explica: "Nueva York es una mezcla de Moisés adolescente, Caín provecto y el bastón fálico de Whitmann, realizando sagrados engendros". Y todavía agrega otra tríada: "El saxofón penetrando en a Biblia, la deshace en innumerables papelillos que caen desde lo alto de los rascacielos'. 
La composición de la historia y la escritura, son por cierto el mismo nivel de la expresión.

La propia novela nos habla del otro nivel simbólico de la tríada. Explicando el simbolismo numérico, se nos dice: "El ternario, volvió Fronesis, el triángulo equilátero, el más bello, según Platón...La Trinidad. El triángulo equilátero era el llamado por los pitagóricos la Athena, la tritogenia, nacida del cerebro de Zeus. Trifolia griega: bien, verdad, belleza. En el tiempo: pasado, presente y futuro. En el espacio: la línea, el plano y el volumen. En la danza clásica de la época de Lully: Fuit, opposition y ensemble. En los misterios: el Padre, el Verbo y el Espíritu Santo'. Es interesante que en este recuento de numerología, sólo una vez se mencione a la Cábala (a propósito del siete: "los signos cabalísticos de los siete días de la creación'”), cuyas correlaciones parecen, sin embargo, subyacer en la novela. Una interpretación cabalística del número 3, por ejemplo, nos dice que lo constituyen el hombre, el mundo y el tiempo: el tiempo precisamente como figura de desplazamiento que modifica y amplía las mutaciones de las otras dos. Lo temporal también es un elemento de la tríada en Lezama, sometido a la cristalización que impone el sujeto, aunque preserva siempre su vibración en el mismo instante figurado. En su "Carta abierta a Lezama Lima"' (recogida en Las palabras de la tribu) José Angel Valente escribe: "Me pregunto también si con ese saber del Padre, remotamente anudado por un cabalista español del siglo XIII, no guarda relación el ahínco con que usted persigue el Mysterium Magnum de Jacobo Boehme, que es, según parece, el místico cristiano más netamente vinculado al mundo de la Cábala"'. En efecto, luego del simbolismo pitagórico la interpretación cabalística parece ser otra de las fuentes de correlación en la novela, especialmente en su proceso de iniciaciones integradoras y en su conversión metafísica; por lo primero, la novela configura una vía de conocimiento; por lo segundo, todos los hechos ganan su sentido en el edificio de la manifestación recuperada por la poesía como figura transcendente. Sobre la tradición pitagorista en nuestras letras, Ricardo Gullón ha escrito un ensayo ilustrativo ("Pitagorismo y modernismo", en Direcciones del modernismo) que justamente muestra la peculiaridad de estas fuentes en su tratamiento hispánico, nada ortodoxo por cierto. La empresa de Lezama Lima mucho más radical que la aventura modernista, si bien tampoco corresponde a las respuestas del simbolismo que ha descrito Northrop Frye en su ensayo "Yeats and the Language of Symbolism" (Fables of Identity), ya que Lezama, a diferencia de Yeats, parte de fuentes más sistemáticas, tramando la audaz confluencia de la patrística y el cabalismo.

La tríada, pues, supone todavía otro valor, aparte de su función expresiva y su implicancia simbólica. Ese tercer valor es el mitopoético. La escritura analógica de Lezama no solamente busca ampliar las significaciones en la comparación de las figuras, busca, en el fondo, convertirse en una nueva lectura del mundo. Por eso, la tradición de que el mundo nos habla se amplía en su obra radicalmente: es el lector de ese mundo el que debe suscitarlo como un alfabeto de figuras combinatorias. En la segunda parte del capítulo XI encontramos el centro de estas especulaciones. José Cemí observa dos estatuillas de bronce en una vitrina, pero advierte que esas figuras "no querian o no podían organizarse en ciudad, retablo o potestades jerarquizadas. Estaban en secreto como impulsadas por un viento de emigración, esperaban tal vez una voz que le dijese al buey, a la bailarina y al guerrero o a la madera, al jade o al cuarzo, la sefral de la partida". Como vemos, el mundo 
no habla por sí mismo: requiere de una voz, de un lector, que desencadene nuevas relaciones entre esos objetos para crear un nuevo espacio. Lo que lleva a Cemí a detenerse ante un objeto (en este caso un objeto de cultura) es, nos dice la novela, "una infinita corriente de analogía, corriente que hacía una regia reverencia, como una tritogenia de gran tamaño, que quería mostrarle su rendimiento, su piel para la caricia y el enigma de su permanencia',

Pero no todos los agrupamientos de la triada suponen aquel espacio nuevo. Lezama también nos explica cómo Cemí advierte que las relaciones entre una copa, un gamo y un ventilador son relaciones discordantes, que no cuajan; coloca entonces la copa entre un ángel y la bacante y ahora sí la coincidencia provee de sentido a la tríada. "Los días que lograba esos agrupamientos donde una corriente de fuerza lograba detenerse en el centro de una composición, Cemí se notaba alegre sin jactancias'. Esas composiciones, agrega, mostraban "la misma existencia de la triangularidad de un triángulo"; esto es: lograban una suficiencia armónica y plena. Al reflexionar sobre "esas recomposiciones espaciales, ese ordenamiento $\mathrm{de}^{*}$ lo invisible", leemos que Cemí "Pudo preciar que esos agrupamientos eran de raíz temporal, que no tenían nada que ver con los agrupamientos espaciales, que son siempre una naturaleza muerta, la fluencia del tiempo convertía al espectador de esas aparentes ciudades espaciales en figuras, por las que el tiempo al pasar y repasar, como los trabajos de las mareas en las plataformas coralinas, formaba como un eterno retorno de las figuras que por estar situadas en la lejanía eran un permanente embrión. La esencia del tiempo, que es lo inasible, por su propio movimiento, que expresa toda distancia, logra reconstruir esas ciudades tibetanas, que gozan de todos los mirajes, la gama de cuarzo de la vía contemplativa, pero en las que no logramos penetrar, pues no le ha sido otorgado al hombre un tiempo en el que todos los animales comiencen a hablarle, todo lo exterior a producir una irradiación que lo reduzca a un ente diamante sin murallas. El hombre sabe que puede penetrar en la única realidad que viene hacia nosotros, que nos muerde, sanguijuela que muerde sin boca, que por una manera completiva que soporta la imagen, como gran parte de la pintura egipcia, nos hiere precisamente con aquello de que carece', Enseguida, otra tríada se establece ante los ojos de Cemí: la que forman las figuras de un grabado; y el autor concluye: "Esos agrupamientos con dimensión que se expresa y con una dirección como soplada eran pensamiento creado, eran animales de imágenes duracionables, que acercaban su cuerpo a la tierra para que él puduiera cabalgarlos".

Vemos, así, que estas imágenes aluden a la potencialidad de una naturaleza que la cultura desdobla, a través de la poesía, en sobrenaturaleza. Y advertimos, por lo mismo, que este método correlativo - al mismo tiempo casual e inducido - trastoca la primera noción sensible del objeto y del nombre en una segunda noción, hiperbólica en tanto figura, y parabólica en tanto espacio mítico. De ese modo, la tría actúa como conversión del mundo en imagen, en morada vuelta a leer. Y esta construcción mitopoética es el proceso y la finalidad no causal de la poesía: la vecindad paradisíaca, que la palabra y la mirada permiten, se establece como la trascendencia verbal del sentido, como su encantamiento y su promesa.

Todavía a propósito de Oppiano Licario, la novela precisa lo siguiente: "La analogía de dos términos de la progresión desarrollaban una tercera progresión o marcha hasta abarcar 
el tercer punto de desconocimiento. En los dos primeros términos pervivía aún mucha nostalgia de la sustancia extensible. Era el hallazgo del tercer punto desconocido, al tiempo de recobrar, el que visualizaba y extraía lentamente de la extensión la analogía de los dos primeros móviles. El ente cognocente lograba su esfera siempre en relación con el tercer móvil errante, desconocido, dado hasta ese momento por las disfrazadas mutaciones de la evocación ancestral...Así, en la intersección de ese ordenamiento espacial de los dos puntos de analogía, con el temporal móvil desconocido, situaba Licario su Silogística poética". Esta cita muestra con nitidez el sistema suscitador de la tríada: de la analogía al otro término que amplía la imagen en su apertura y en su cumplimiento. Es aquí que se produce la respuesta de Lezama al método crítico de Eliot: su opción es el camino opuesto, el método mitopoético, en el cual la palabra siempre accede a una realidad más amplia. Esta "inicial morfología"' no se detiene en los objetos: sabemos ya que trastoca la historia y la cultura en eras imaginarias. La novela añade que "Las situaciones históricas eran para Licario una concurrencia fijada en la temporalidad, pero que seguían en sus nuevas posibles combinatorias su ofrecimiento de perenne surgimiento en el tiempo"'.

Ahora bien, si atendemos al esquema mismo de la tríada observaremos que sus tres imágenes son los tres términos de la metáfora. En efecto, el esquema es aquí metafórico (dos términos que aluden a uno tercero), sólo que este tercer término aparece ahora convocado y plasmado. Es por esto que la silogística o sistema, que empieza como un método expositivo y como una estructura de composicion, termina presentándose como un pensamiento poético. Porque frente al proceso deductivo y racional del esquema dialéctico, el esquema metafórico supone un movimiento inductivo y sobrereal. Pero sobre todo supone la equivalencia de sus tres elementos, es decir, la simultaneidad y la instantaneidad de los mismos. $\mathrm{Y}$, justamente, es como pensamiento poético que se resuelve esta metodología. Porque no sólo implica la crítica al pensamiento dualista, al suponer una integración simultánea, sino también una crítica al deductivismo racional al poner en movimiento un sistema de aprehensión cuyo objeto descubierto opera en la suficiencia de los mitos.

En el nivel de la instrumentación expresiva, Lezama coincide con algunas exploraciones del surrealismo y con más próximas experiencias de Julio Cortázar, cuyas últimas novelas persiguen asimismo una correlación de figuras en confluencia; y con el pensamiento poético de Octavio $\mathrm{Paz}$, que en la analogía busca hacer coincidir, por el valor del instante conjugador, el lenguaje y el mundo, la conciencia y la multiplicidad.

Las correlaciones reclaman también deslindes, y quizá el más importante en Paradiso es el que se establece frente a Nietzsche, cuyas ideas ya había discutido Lezama en su ensayo "Introducción a un sistema poético". Es particularmente interesante la crítica a Nietzsche, porque parte de la perspectiva religiosa, pero sobre todo porque plantea una defensa de la cultura griega subterránea, el orfismo y el pitagorismo. Lezama incluso se separa del espíritu dionisíaco proclamado por la obra de Nietzsche, a pesar de la exhuberante sensorialidad de Paradiso. Pero es posible que esa exhuberancia sea también una parte de la figura a leer, ya que la novela no rehusa ningún extremo de la realidad humana, y más bien busca superar los contrarios y mostrar la doble valencia de los hechos; no es casual que incluso el fibroma que operan a la madre sea contemplado en la novela como un objeto necesario y deslumbrante. Nada es excluyente en este sistema poético; los hechos humanos poseen tensiones polares, altas y bajas mareas, que se.precisan en la inmediatez sensorial y 
en la resonancia metafísica. Y en la parte infernal de la figura erótica no hay que olvidar tampoco el humor festivo de su tratamiento. Probablemente, Lezama está más cerca en este sentido del sensorialismo incorporador de Claudel. " $\mathrm{La}$ obra de arte es el resultado de la colaboración de la imaginación con el deseo", escribió éste en su "Lettre a l'abbé Bremond". Pero, como hemos dicho, Lezama parece equidistar de Claudel gracias a su cultivo de Mallarmé. En Paradiso leemos: "La ausencia no era nunca para él (para Cemí) ese Génesis al revés, que se ha señalado en Mallarmé, por el contrario era tan naturaleza. como los cuerpos desenvolviendo las proporciones del ritmo". Sin embargo, también en Lezama la imagen actúa desde el reclamo mallarmeano de una palabra que "dota así de autencidad a nuestra morada". La "desaparición vibratoria" del hecho natural en la palabra, que definía la poesía para Mallarmé, se convierte en Lezama en la abundancia vibratoria de ese hecho, ahora sobrenatural.

Julio Ramón Ribeyro ("Notas sobre Paradiso", Recopilacion de textos sobre José Lezama Lima, 1970) ha señalado los paralelismos entre el librọ de Proust y el de Lezama. Hay todavía otras dos correlaciones: la lectura que hace Lezama de los personajes a través de las secretas señales de la fisonomía, esa suerte de conductismo interior, aparece profusamente en el libro de Proust; y es de los mecanismos que en uno y otro conducen la elaborada penetración de un lenguaje que caracteriza. La otra coincidencia está en el empleo de los datos culturales para el mecanismo de la comparación, lo que es, por cierto, más libre en Lezama. A propósito de Francois, la cocinera de la familia, que como dice Ribeyro parece evocada en Baldovina, Proust escribe: "Y ya desde el día antes, Francisca, contentísima por poder entregarse a ese arte de la cocina, para el que tenía indudablemente nativa aptitud, y estimulada además por el anuncio de un invitado nuevo, sabía que tendría que confeccionar, con arreglo a los métodos que nadie más que ella conocía, vaca a la gelatina, y vivía en la efervescencia de la creación; como concedía extrema importancia a la calidad intrínsica de los materiales que debían entrar en la fabricación de su obra, fue ella misma al Mercado Central para que le dieran los mejores brazuelos para "romstec" y los jarretes de vaca y pies de ternera más hermosos, lo mismo que se pasaba Miguel Angel ocho meses en las mantañas de Carrara para escoger los más bellos bloques de mármol con destino al monumento de Julio II. Y tal ardor desplegaba Francisca en estas idas y venidas, que mamá, al verla con el rostro encendido, temía que se pusiera mala de trabajar, como le pasó al autor del sepulcro de los Medicis en las canteras de Pietraganta'. Baste esta coincidencia menor; $\tan$ lezamesca por lo demás, ya que desde la biblioteca de José Cemí la tradición gana otros ecos.

Para terminar, volvamos a Novalis. He partido de él, no para sugerir su influencia en Lezama, sino, más bien, para deducir las correlaciones que se establecen al transformarse la tradición de uno a otro. Pero esa correlación no es de ningún modo casual. En el deslinde teórico que es el ensayo "Introducción a un sistema poético", al precisar su separación ante la poética aristotélica de la imitación, Lezama Lima escribe: "Antes del gran ordenamiento aristotélico, afanoso de aclarar las concepciones de la poesía como oposición a tecné, es decir, como ser universal y padre universal. Y que retorna en el absoluto de los idealistas alemanes de Hegel a Novalis, situando siempre a la poesia en el ser principio, en la total causalidad inmanente. En la poesía como lo real absoluto, y la filosofía como la operación absoluta, de Novalis, reaparece esa concepción griega primigenia, del ser 
universal de la poesía, en oposición a los alemanes neoclásicos dal período de Lessing que juraban por la poética aristotélica como si fuese el escudo de Aquiles'. Advertimos, así, que la correlación con Novalis tiene un origen más remoto, que hunde sus raíces en tradición subterránea que Lezama actualiza: la concepción órfica de la palabra poética como revelación. En Paradiso se menciona una sola vez a Novalis, y desde una réplica de Foción, que sabemos actúa como el antagonista frente a Fronesis: "Un párrafo más y te oímos citar a Novalis, a la flor azul y el amor reinventado"; desde la réplica, la frase sugiere que Fronesis asume la gravitación de Novalis, y la mención a la "flor azul" es, por cierto, una directa evocación del Heinrich von Ofterdingen. De algún modo, la novela inconclusa de Novalis (que en su visión mística de la poesía había concebido como el primer libro de una Biblia moderna) se cumple en la más desarrollada y compleja novela de Lezama. La aventura y certidumbre del ejercicio poético adquieren en Paradiso la forma sistemática de un conocimiento que se ilustra a sí mismo como historia novelesca, y que nos convoca con su capacidad especulativa para un diálogo renovado sobre el destino de la poesia. 
